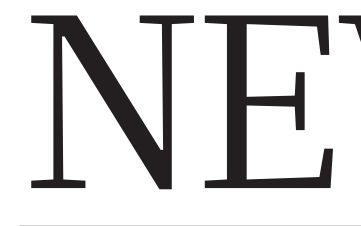

ASTRONOMY From fireball to fragments, a portrait of the Siberian meteor $\mathbf{p} \mathbf{1 6}$
PHYsICs A material advance for energy-efficient transistors? p.17
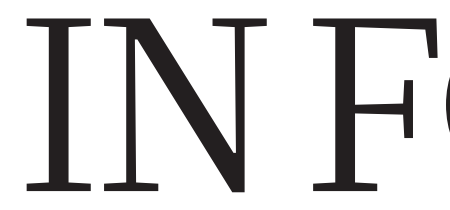

NEUROSCIENCE Masterminds of the US Brain Activity Map project $\mathbf{p} .19$
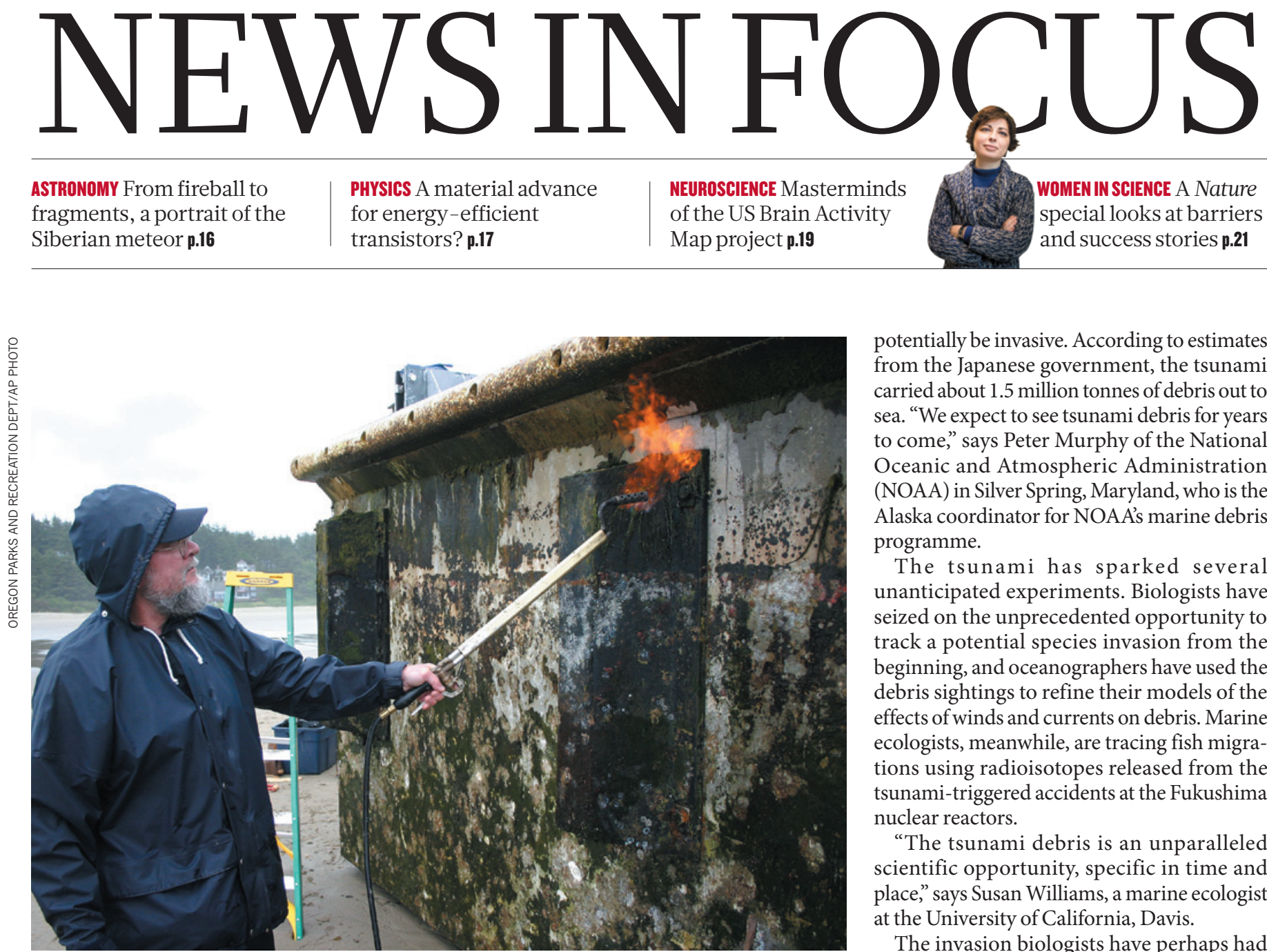

A worker in Newport, Oregon, burns debris off a Japanese concrete dock that washed across the Pacific.

\title{
ECOLOGY
}

\section{Tsunami triggers invasion concerns}

\section{Biologists track species on flotsam from Japan to US shores.}

\section{BY VIRGINIA GEWIN}

$\mathrm{W}$

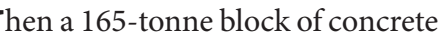
and steel crashed into the central Oregon coast last June, Jessica Miller was shocked to find that the structure a dock that had washed across the Pacific from Misawa, Japan — was teeming with life after 15 months at sea. "It was surreal," says Miller, a marine ecologist at Oregon State University's Hatfield Marine Science Center in Newport. She found tens of thousands of organisms on the structure in layers up to 15 centimetres thick, including brown algae, pink barnacles and shrimp-like creatures called caprellids. In
December 2012, a second large Japanese dock landed in Washington state laden with species. Other debris, including derelict boats and buoys harbouring live organisms, continues to wash up on the shores of Oregon, Washington and, most recently, Hawaii.

Almost two years after the Tohoku earthquake triggered a devastating tsunami, North American shores are awash in debris swept

\section{ONATURE.COM}

For more on the

Tohoku tsunami, see

the Nature special:

nature.com/japanquake from the Japanese coastline some 8,000 kilometres away. The flotsam constitutes floating islands of species some of which could potentially be invasive. According to estimates from the Japanese government, the tsunami carried about 1.5 million tonnes of debris out to sea. "We expect to see tsunami debris for years to come," says Peter Murphy of the National Oceanic and Atmospheric Administration (NOAA) in Silver Spring, Maryland, who is the Alaska coordinator for NOAA's marine debris programme.

The tsunami has sparked several unanticipated experiments. Biologists have seized on the unprecedented opportunity to track a potential species invasion from the beginning, and oceanographers have used the debris sightings to refine their models of the effects of winds and currents on debris. Marine ecologists, meanwhile, are tracing fish migrations using radioisotopes released from the tsunami-triggered accidents at the Fukushima nuclear reactors.

"The tsunami debris is an unparalleled scientific opportunity, specific in time and place," says Susan Williams, a marine ecologist at the University of California, Davis.

The invasion biologists have perhaps had the most urgent call to action, because no one anticipated that coastal species would survive such a long journey across the open sea. "This is an event so rare we simply don't expect to see it," says James Carlton, an invasive-species expert from Williams College in Williamstown, Massachusetts, who has teamed up with Miller and other colleagues to study the arrivals.

Researchers must first confirm that the debris they are studying really is from the tsunami. Water bottles with Japanese characters offer a clue. Registration numbers on boats can be traced back to those that were reported missing. But of the 1,500 or so reported items that have washed up in recent months, only 21 have been confirmed by the Japanese consulate, according to Murphy.

The arrival of potentially invasive species is not a new concern on the Pacific coast. Organisms can be transported on transoceanic boats or in their ballast water. But boats do not typically recruit whole communities, and they move too fast between ports for many organisms to hang on. The resident coastal communities transported on slow-moving tsunami debris therefore look very different - and can arrive along the whole North American coastline rather than just at heavily monitored ports. No invasions have yet been detected 


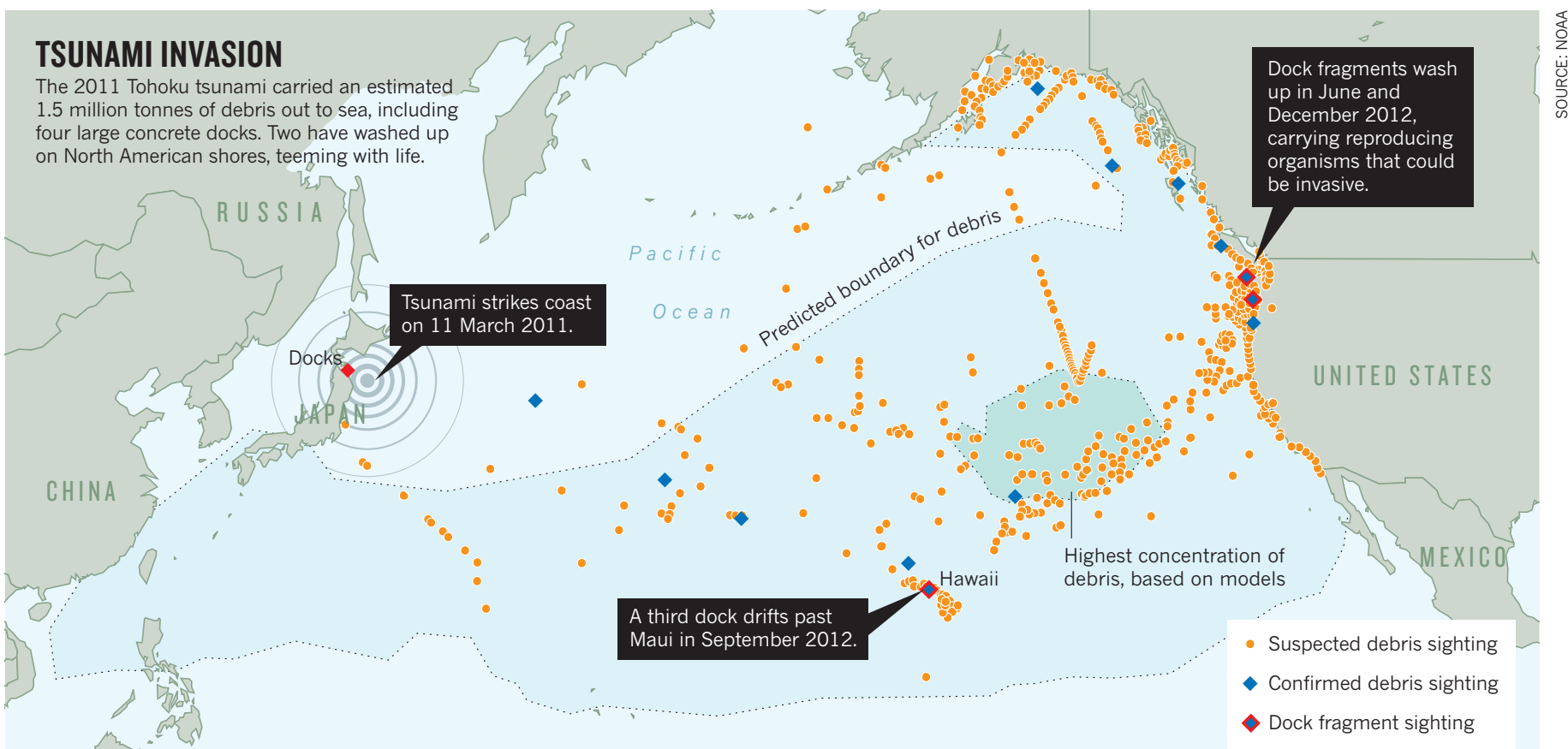

from the tsunami debris, but it is unlikely that Carlton, Miller and their team are aware of every single landfall, so a potentially invasive species could well have been missed.

The team's next step is to determine which organisms survived the journey across the Pacific, and how. In the nine months since the first dock made landfall, the team has identified roughly half of the 175 species found so far on all debris items. John Chapman, a marine biologist also at Hatfield Marine Science Center, will go to Misawa later this month to document which species reside on docks there in early spring, the season when the tsunami struck.

The results so far suggest a real risk of invasion. For example, three of the best-known algal invaders have been among the debris, says Gayle Hansen, a marine-algae expert at Oregon State University who is based in Newport. She says that $75 \%$ of the 46 algal species she has collected from the debris so far have been reproductively active, dropping spores. That gives them a good chance of getting established and possibly displacing native species in the Pacific Northwest.

State officials, who are usually first on the scene, are often quick to destroy any organisms clinging to debris to avert potential invasions. That can make it challenging for Carlton's team to get samples. But the problem is easing, Carlton says, as more responders become aware of the need to sample the arrivals. He adds that there have been few reports of debris with living Japanese species from Alaska, British Columbia and California, which could represent a lack of reporting, or an artefact of oceanography.

The recent spike in debris landings is to be expected during winter and spring, owing to large-scale patterns of currents and winds. The path of debris flows north of Hawaii (see 'Tsunami invasion') and was predicted by NOAA models, which have incorporated sightings from mariners. But Nikolai Maximenko, an oceanographer at the University of Hawaii in Honolulu, says that the exact landfall for the concrete docks was difficult to predict because they are buoyant enough that the effects of winds and currents are comparable in strength.

Maximenko is also helping to sample the plume of Fukushima radioisotopes, which lags behind the debris and is slowly moving east. The radioisotopes are assisting ecologists. In February, Nicholas Fisher, a marine scientist at Stony Brook University in New York, and his colleagues showed that two radioisotopes, caesium-134 and caesium-137, could be used to trace the past movements of bluefin tuna between Japan and California (D. J. Madigan et al. Environ. Sci. Technol. http://doi.org/kn9; 2013). Fisher's team confirmed the presence of both caesium isotopes in bluefin tuna arriving from Japan - although the levels pose no health risk to humans. "We see evidence that fish might cross the Pacific in about one month, which we found amazing," says Fisher.

Other researchers from Oregon State University in Corvallis and NOAA are using the technique to determine whether there are two different stocks of North Pacific albacore tuna, which would be reflected in each population's isotopic profile. Fisher's team also wants to use this method to track the migratory patterns of other large marine animals, such as albatrosses, loggerhead turtles and salmon sharks.

Even as researchers track species using radioisotopes and count them on debris, they bear in mind the tsunami's staggering human toll. "This is the experiment that never should have taken place," says Chapman.

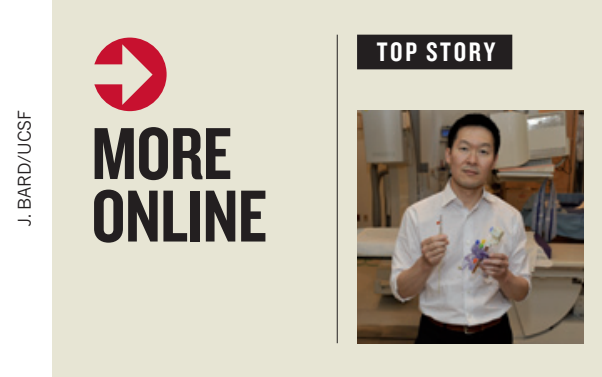

Bendable needles could facilitate delivery of stem cells to the brain go.nature. com/radv2c

\section{MORE NEWS}

- Intercontinental mind-meld links rats and sparks scepticism go.nature. com/5stiji

- Richard l's heart shows Christians practised embalming go.nature.com/ocfslz - Having sons can shorten a woman's life expectancy go.nature.com/wcfpgf

\section{VIDEO}

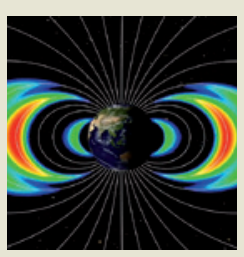

Third ring

of radiation makes surprise appearance around Earth, then disappears go.nature.com/iqvogh 